\title{
Editorial: The President's Message
}

June 19, 2005

Dear Imanites,

Assalamu Alaykum.

It is after a long pause that you have JIMA in your hand. We apologize for this long delay.

JIMA has been the mouthpiece of IMANA

for a long time. It has been the link between Muslim physicians in North America and Muslim physicians in other countries. Unfortunately, it has not been published for the last two years or so. The Executive Council, recognizing its importance, coupled with the concern expressed by many members about its non-publication, asked Dr. Hossam Fadel, who had been the editor for 15 years through November 2000, to resume editorship. Alhamdulliah, he accepted this hard job. Dr. Fadel asked to be helped in this endeavor by Dr. Faroque Khan and Dr. Hussain Nagamia, and they accepted.

We ask you to support JIMA both academically and financially. We pray for the success of JIMA.

You must have noticed our regular IMANA newsletter, the contents and quality speaks for itself. Thanks to Dr. Rehana Kausar who has taken personal interest in this publication, keeping us informed of recent and upcoming events. Of course, this does not replace JIMA.

Let me update you about IMANA. Since JIMA was in your hand last time your organization has progressed well and far beyond the expectations of the majority. We are now housed in a new facility, which gives a professional appearance to the IMANA organization representing thousands of Muslim physicians in North America and beyond. Young blood has been infused for stability and now we have a growing membership in all categories. Our Ethics Committee has come out with answers to many of the problems Muslim physicians and communities face in the very technologically and scientifically advancing field of medicine. The committee, led by Dr. Shahid Athar, chairman of the Board of Regents, deserves all the praise for its tireless work. The position paper on medical ethics is in great demand, and many Muslim scholars are requesting copies of the manuscript.

In regards to relief work, I am proud to mention the names of Dr. Pervaiz Malik, our past president, and Dr. Rehana Kausar, our President-Elect, who took IMANA's mission to serve humanity in the Tsunami destroyed areas of Banda Aceh and other parts of Indonesia. IMANA is helping build a clinic there and we definitely need your help in all the facets of this noble work.

Our national/international conventions continue to improve both in numbers and the quality of CME papers that are presented. This year our annual convention will be held in San Francisco in July followed by a pre ISNA convention in Chicago. We plan to go to China in July and Qatar in December of 2006. We are now offering from 30 to 50 category one CME hours annually.

The entire executive council wants you to get involved in your organization. We have made accountability very transparent and we are committed to infuse young and enthusiastic blood into IMANA and in sha' Allah you will see a better IMANA as time goes by. Thanks for your patience. May Allah (SWT) bless you and your family.

That is all for the moment. See you in San Francisco.

Farooq I. Selod, M.D. President, IMANA 